\title{
Health and productivity at work: which active workstation for which benefits: a systematic review
}

\author{
Francois Dupont, ${ }^{1}$ Pierre-Majorique Léger, ${ }^{2}$ Mickael Begon, ${ }^{1,3}$ François Lecot, ${ }^{1}$ \\ Sylvain Sénécal, ${ }^{2}$ Elise Labonté-Lemoyne, ${ }^{2}$ Marie-Eve Mathieu, ${ }^{1,3}$
}

'École de kinésiologie et des sciences de l'activité physique, Université de Montréal, Montreal, Quebec, Canada ${ }^{2}$ Tech3Lab, HEC Montréal, Montreal, Quebec, Canada ${ }^{3}$ Research Center, Sainte-Justine University Hospital Center, Montreal, Quebec, Canada

\section{Correspondence to}

Professor Marie-Eve Mathieu, École de kinésiologie et des sciences de l'activité physique, Universite de Montreal, Montreal, QC H3T1J4, Canada; me.mathieu@umontreal.ca

Received 30 July 2018 Revised 19 November 2018 Accepted 26 November 2018 Published Online First 28 January 2019

\section{Linked}

- http://dx.doi.org/10.1136/ oemed-2018-105671

\section{Check for updates}

(C) Author(s) (or their employer(s)) 2019. No commercial re-use. See rights and permissions. Published by BMJ.

To cite: Dupont $F$, Léger P-M, Begon $M$, et al. Occup Environ Med 2019:76:281-294

\section{ABSTRACT}

In order to reduce sedentary behaviour at work, research has examined the effectiveness of active workstations. However, despite their relevance in replacing conventional desks, the comparison between types of active workstations and their respective benefits remains unclear. The purpose of this review article is thus to compare the benefits between standing, treadmill and cycling workstations. Search criteria explored Embase, PubMed and Web of Science databases. The review included studies concerning adults using at least two types of active workstations, evaluating biomechanical, physiological work performance and/or psychobiological outcomes. Twelve original articles were included. Treadmill workstations induced greater movement/activity and greater muscular activity in the upper limbs compared with standing workstations. Treadmill and cycling workstations resulted in elevated heart rate, decreased ambulatory blood pressure and increased energy expenditure during the workday compared with standing workstations. Treadmill workstations reduced fine motor skill function (ie, typing, mouse pointing and combined keyboard/mouse tasks) compared with cycling and standing workstations. Cycling workstations resulted in improved simple processing task speeds compared with standing and treadmill workstations. Treadmill and cycling workstations increased arousal and decreased boredom compared with standing workstations. The benefits associated with each type of active workstation (eg, standing, treadmill, cycling) may not be equivalent. Overall, cycling and treadmill workstations appear to provide greater short-term physiological changes than standing workstations that could potentially lead to better health. Cycling, treadmill and standing workstations appear to show short-term productivity benefits; however, treadmill workstations can reduce the performance of computer tasks.

\section{INTRODUCTION}

In 2013, costs associated with sedentary behaviour were estimated at $\$ 65.5$ billion worldwide. ${ }^{1}$ Moreover, a shift from manual labour jobs to highly sedentary service industry and office-based professions has been observed over the last decades. ${ }^{2}$ Recently, researchers have begun to study interventions designed to break up and reduce sedentary time throughout the workday by replacing the sitting workstation, which promotes sedentary behaviour, ${ }^{3}$ with active workstations.

\section{Key messages}

What is already known about this subject?

- Physical demands in the work environment have declined in Western countries over the last decades resulting in new types of negative health concerns.

- Active workstations such as standing, walking and cycling may reduce sitting time and could enhance health and productivity at work.

\section{What are the new findings?}

- The benefits associated with each type of active workstation (eg, standing, treadmill, cycling) may not be equivalent.

- Cycling and treadmill workstations appear to provide greater short-term physiological changes than standing workstations that could potentially lead to better health.

- Cycling, treadmill and standing workstations appear to show short-term productivity benefits, while treadmill workstations reduce the performance of computer-related work.

\section{How might this impact on policy or clinical practice in the foreseeable future? \\ - These results are relevant in order to optimise future workplace interventions. \\ - Workers and corporations should be able to look at the benefits and limits of each type of workstation and determine which one is most appropriate for workers' specific needs and tasks.}

Standing, treadmill or cycling workstations change the ergonomic paradigm of the 09:0017:00 workday, allowing a change in posture (ie, sitting vs standing) and improved muscle activation (ie, none vs muscular contractions) during work activities (figure 1). Many studies suggest that active workstations could reduce sedentary time at work, ${ }^{4-6}$ maintain work productivity, ${ }^{6}$ increase energy expenditure, ${ }^{7}$ regulate high blood pressure,${ }^{8}$ relieve back pain, ${ }^{9}$ enhance positive affect ${ }^{10}$ and increase cognitive abilities ${ }^{11} \mathrm{com}$ pared with conventional seated workstations.

Considering the growing body of evidence that suggests that standing, treadmill and cycling workstations may improve health and productivity at work compared with seated workstations, it would be relevant to have a better understanding of what benefits are specific to each of these active workstations. The purpose of this review article is thus 


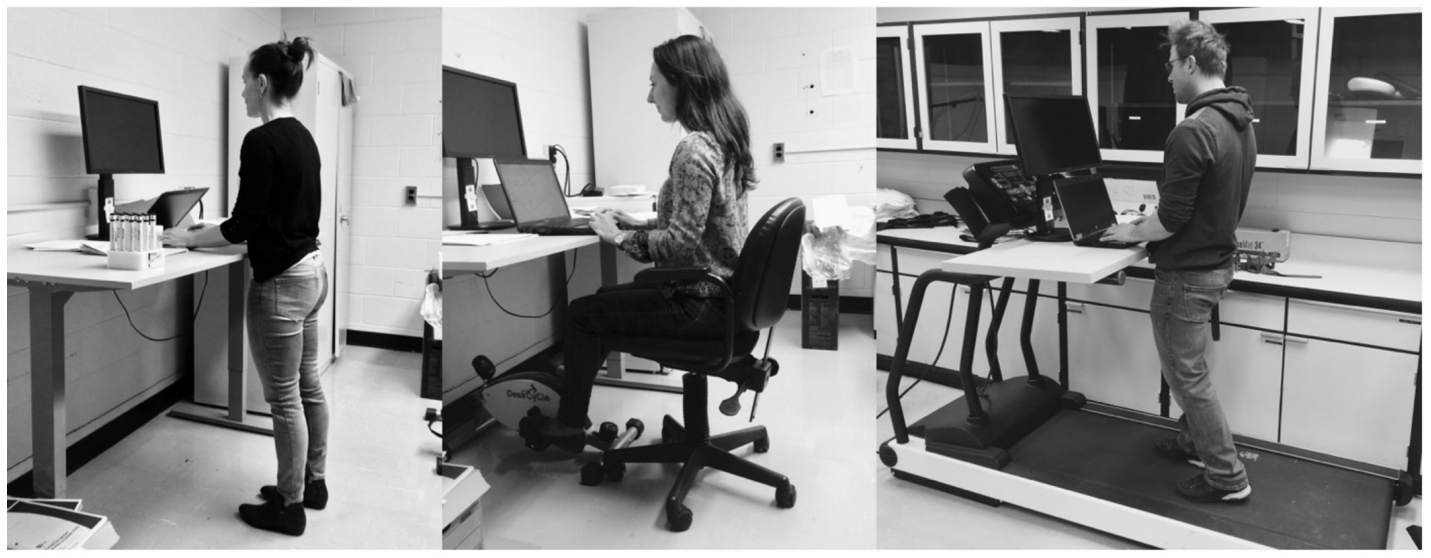

Standing Workstation Cycling Workstation

Treadmill Workstation

Figure 1 Type of active workstations included in the systematic review.

to compare the benefits between standing, treadmill and cycling workstations.

\section{METHODS}

\section{Eligibility and exclusion criteria}

To be included in this review, studies were required to be published in peer-reviewed academic journals, written in English and respect Participants, Interventions, Comparators, Outcomes, Study criteria (table 1). Participant criteria included adult population, healthy or with cardiometabolic disorders and free of musculoskeletal complaints. Studies were required to include at least two types of active workstations. Both laboratory and free-living environment intervention protocols were included. Studies also needed to evaluate biomechanical, physiological, psychobiological and/or cognitive outcomes. Studies

\begin{tabular}{|c|c|}
\hline PICOS & Details \\
\hline Participants & $\begin{array}{l}\text { At least } 18 \text { years old. Adults presenting cardiometabolic } \\
\text { disorders and healthy adults. }\end{array}$ \\
\hline Interventions & $\begin{array}{l}\text { Intervention with conventional seats, seated active } \\
\text { workstations (eg, cycling desk and elliptical pedal desk) } \\
\text { and upright active workstations (eg, standing desk, } \\
\text { treadmill desk). Interventions were performed in a } \\
\text { laboratory or free-living environment. }\end{array}$ \\
\hline Comparative factors & $\begin{array}{l}\text { Different types of workstations (ie, standing, treadmill, } \\
\text { recumbent pedal, elliptical pedal and cycling). }\end{array}$ \\
\hline Outcomes & $\begin{array}{l}\text { Biomechanical: measurement of muscle activation, posture } \\
\text { and joint angles, as well as kinematics. } \\
\text { Physiological: heart rate, oxygen consumption, energy } \\
\text { expenditure, blood pressure, perceived exertion and } \\
\text { pressure pain thresholds. } \\
\text { Work performance: quantitative and qualitative } \\
\text { measurements of typing, mouse pointing, multitasking, } \\
\text { perception of task, attention to task, speech assessment } \\
\text { and memory tasks. } \\
\text { Psychobiological: quantitative and qualitative } \\
\text { measurement of arousal, stress, boredom, task satisfaction, } \\
\text { and quantitative measurement of salivary cortisol and } \\
\text { encephalography. }\end{array}$ \\
\hline Study designs & $\begin{array}{l}\text { Pilot study, randomised cross-over full-factorial study, } \\
\text { randomised repeated measures design, within participant } \\
\text { experimental design, experimental mixed-model study. }\end{array}$ \\
\hline
\end{tabular}

were excluded if active workstations were not standing, treadmill or cycling based, and included 'interest of use' or 'social acceptance' outcomes.

\section{Literature search and study selection}

A computer-assisted systematic search of Central, Embase, PubMed and Web of Science databases was conducted on 13 March 2018 and included all studies prior to that date. The following keywords were used: 'desks', 'workstation', “work station, "works station and the following Boolean phrase: active OR bik* OR cycling OR 'height adjustable' OR stepping OR 'stand up' OR standing OR treadmill* OR walk* OR elliptical OR bicycl* OR pedaling OR 'stability ball' OR 'stability balls' OR 'exercise ball' OR 'exercise balls' OR 'swiss ball' OR 'swiss balls' OR 'sit-to-stand' OR 'sit stand'.

A first study selection was completed independently by two reviewers (FD, FL) based on the 'inclusion of at least two active workstations' by screening titles and abstracts. A final selection was made according to eligibility criteria by one reviewer (FD) using full texts.

\section{Data extraction and results presentation}

Data extraction process was completed by FD. Relevant outcomes were collected, analysed and summarised. Only significant differences (ie, mean values, z-scores, percentile, and so on) were reported in the review. Effect size (Cohen's $d$ ) has been calculated for all significant differences.

\section{Quality assessment}

Two authors (FD, FL) used the modified Downs and Black checklist ${ }^{12}$ based on 27 'yes'-or-'no' items across five sections of quality assessments to determine risk of bias: (1) study quality; (2) external validity; (3) study bias; (4) confounding and selection bias; and (5) power of the study.

\section{RESULTS}

Out of the 1352 studies identified through computer search, 274 examined the effects of active workstations (figure 2). Twelve studies met eligibility criteria (table 2) and their quality was assessed (table 3). Studies were diverse in terms of outcomes, measures and study design. Selected studies used different taxonomies to define 'active workstation', and we regrouped them as follows: (1) standing workstations, (2) walking workstations 


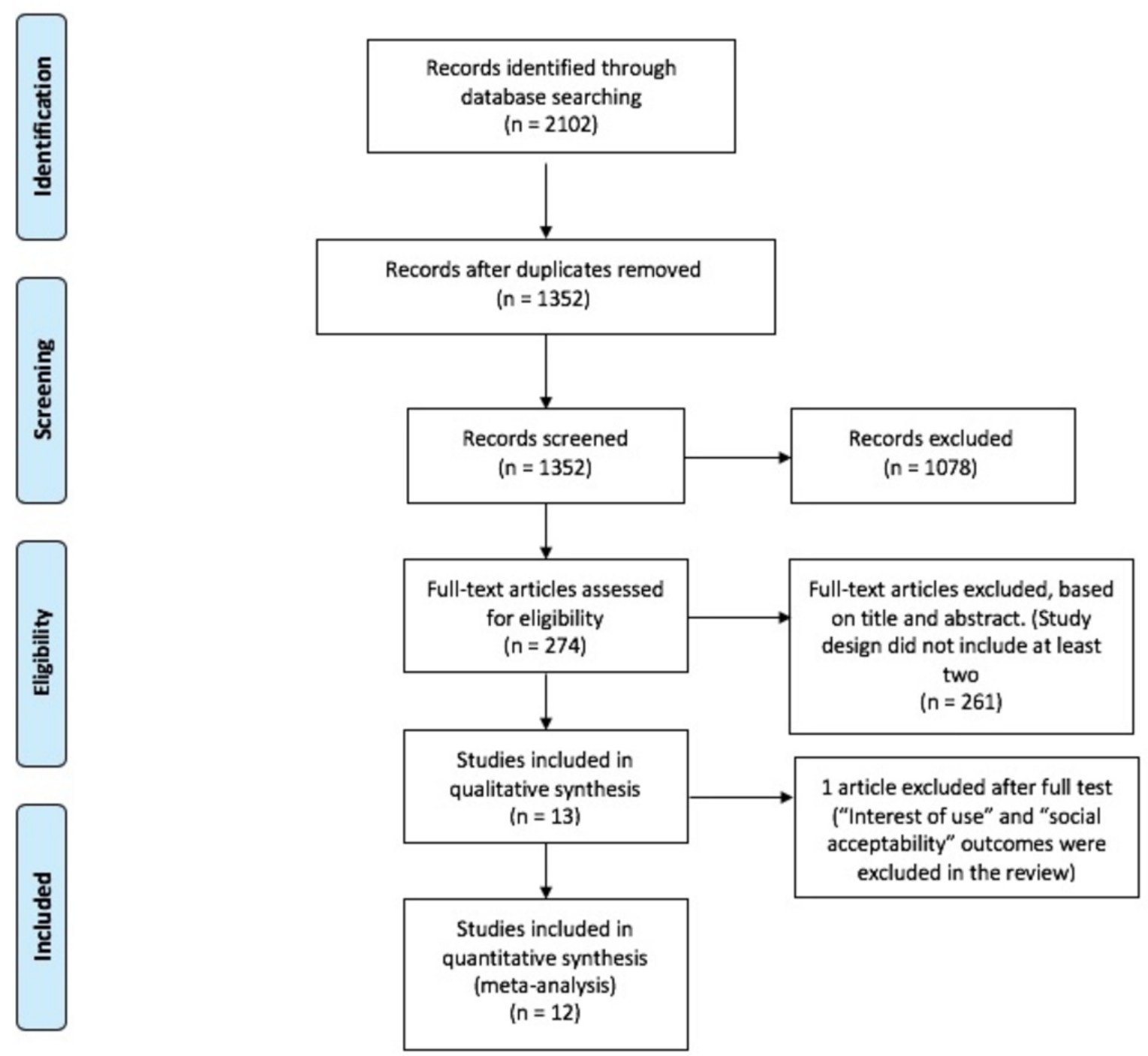

Figure 2 Preferred Reporting Items for Systematic Reviews and Meta-Analyses (PRISMA) flow diagram.

(speed expressed in $\mathrm{km} /$ hour), and (3) pedalling/elliptical workstations (power expressed in watts (W) and in maximum aerobic power (MAP)). Conventional seated workstations were present in selected studies, but are beyond the scope of the present review.

\section{Musculoskeletal activity}

One study ${ }^{13}$ examined the biomechanics of three active workstations using electromyography of the trapezius and erector spinae, trunk and head 3D kinematics and physical activity quantified by accelerometers on the legs, trunk and arms. Twelve participants were asked to complete general office tasks (ie, typing, reading, correction, telephone use, mouse dexterity and cognitive tasks) while using active workstations. An increase in right trapezius activity was observed from standing to treadmill $2.5 \mathrm{~km} / \mathrm{hour}$ workstations: $3.8 \%$ vs $8.1 \%$ of maximum voluntary contraction (median values), respectively. Also, all variables concerning the intensity of movement (median and 95th percentile) increased in

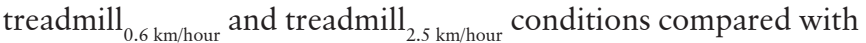
standing, except for the physical activity intensity of the head at the 95 th percentile for treadmill ${ }_{0.6 \mathrm{~km} / \mathrm{hour}}$ which remained similar to the standing condition.

\section{Physiological activity}

Six studies ${ }^{8}$ 13-17 $^{13}$ reported physiological outcomes. Four ${ }^{13-16}$ included adults with no health issues $(n=109)$ and two studies 817 included adults with overweight or class 1 obesity who also had prehypertension or impaired fasting glucose $(n=22)$. From those four studies, mean heart rate (HR), blood pressure, energy expenditure, perceived exertion and pressure pain thresholds were assessed. All studies except one ${ }^{17}$ showed no difference between workstations.

\section{Mean HR}

Increased HR was observed in all four studies ${ }^{813-15}$ when using treadmill or cycling compared with standing workstations. Specifically, Botter et $a l^{13}$ reported an increase of 12 beats per minute (bpm) using a treadmill $2.5 \mathrm{~km} / \mathrm{hour}(91 \mathrm{bpm})$ compared with standing $(79 \mathrm{bpm})$, which was corroborated by Cox et al. ${ }^{14}$ Moreover, Straker et al ${ }^{15}$ reported an increase of $5 \mathrm{bmp}$ for the treadmill $_{3.2 \mathrm{~km} / \mathrm{hour}}$ and an increase of $7 \mathrm{bmp}$ for cycling ${ }_{30 \mathrm{w}}$ compared with standing workstations. All other conditions with lower power or speed (eg, treadmill $1_{1.6 \mathrm{~km} / \mathrm{hour}}$; cycling $_{5 \mathrm{w}}$ ) did not result in an increase in bmp. Zeigler et al ${ }^{8}$ monitored HR during a 12-hour period (08:00-20:00) and were specifically interested in two periods (ie, work hours (08:00-16:00) and postwork 


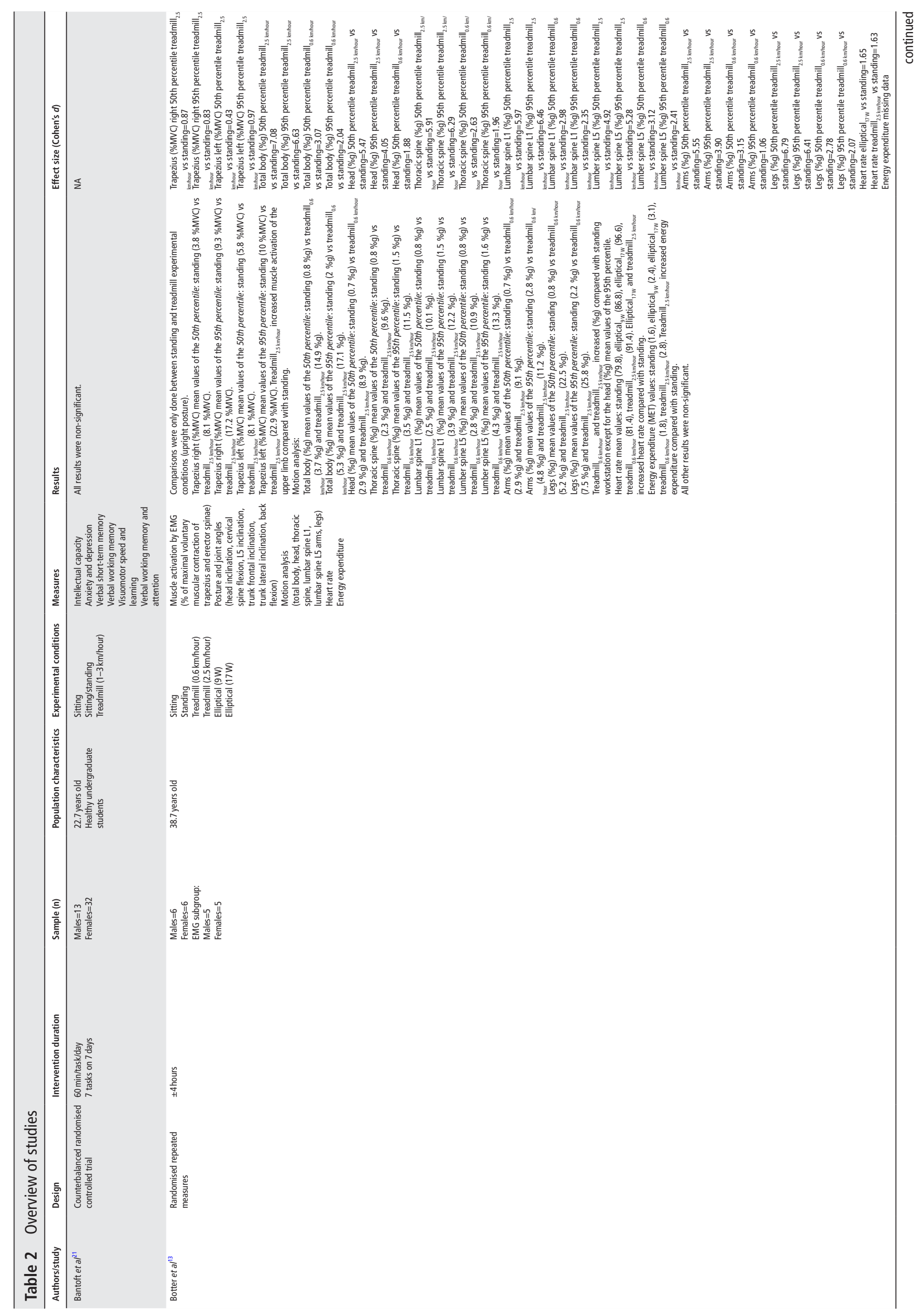




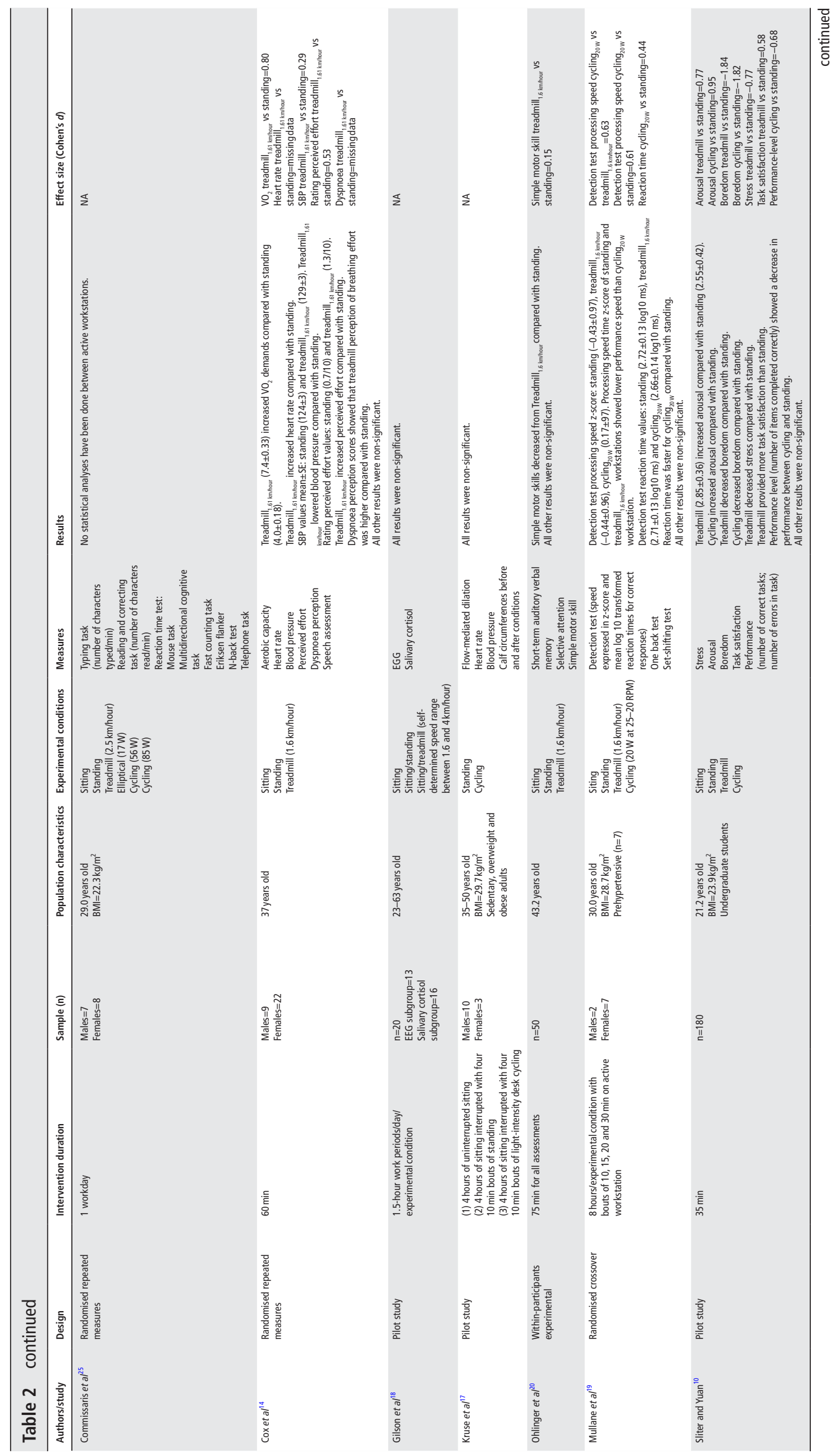




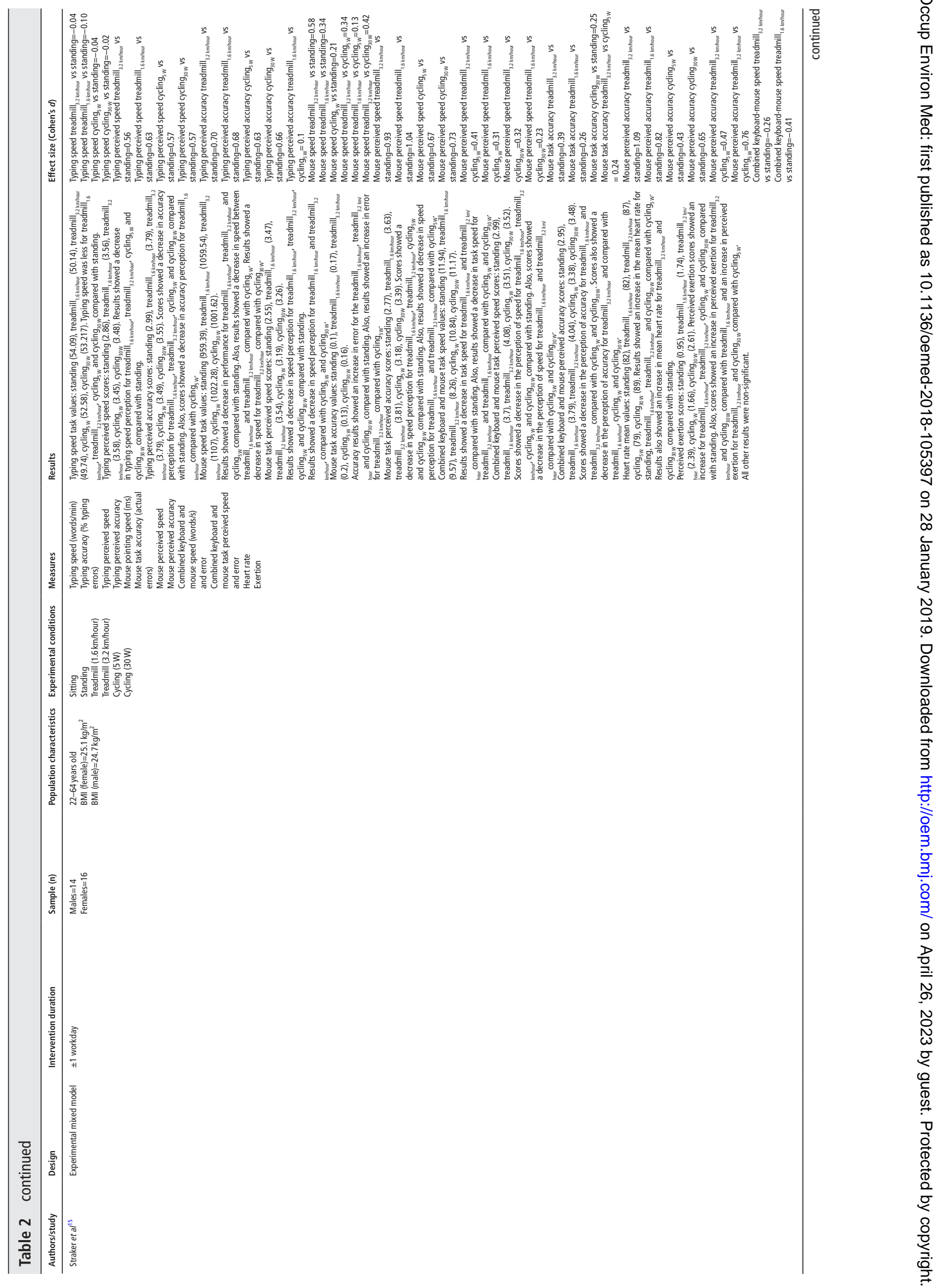




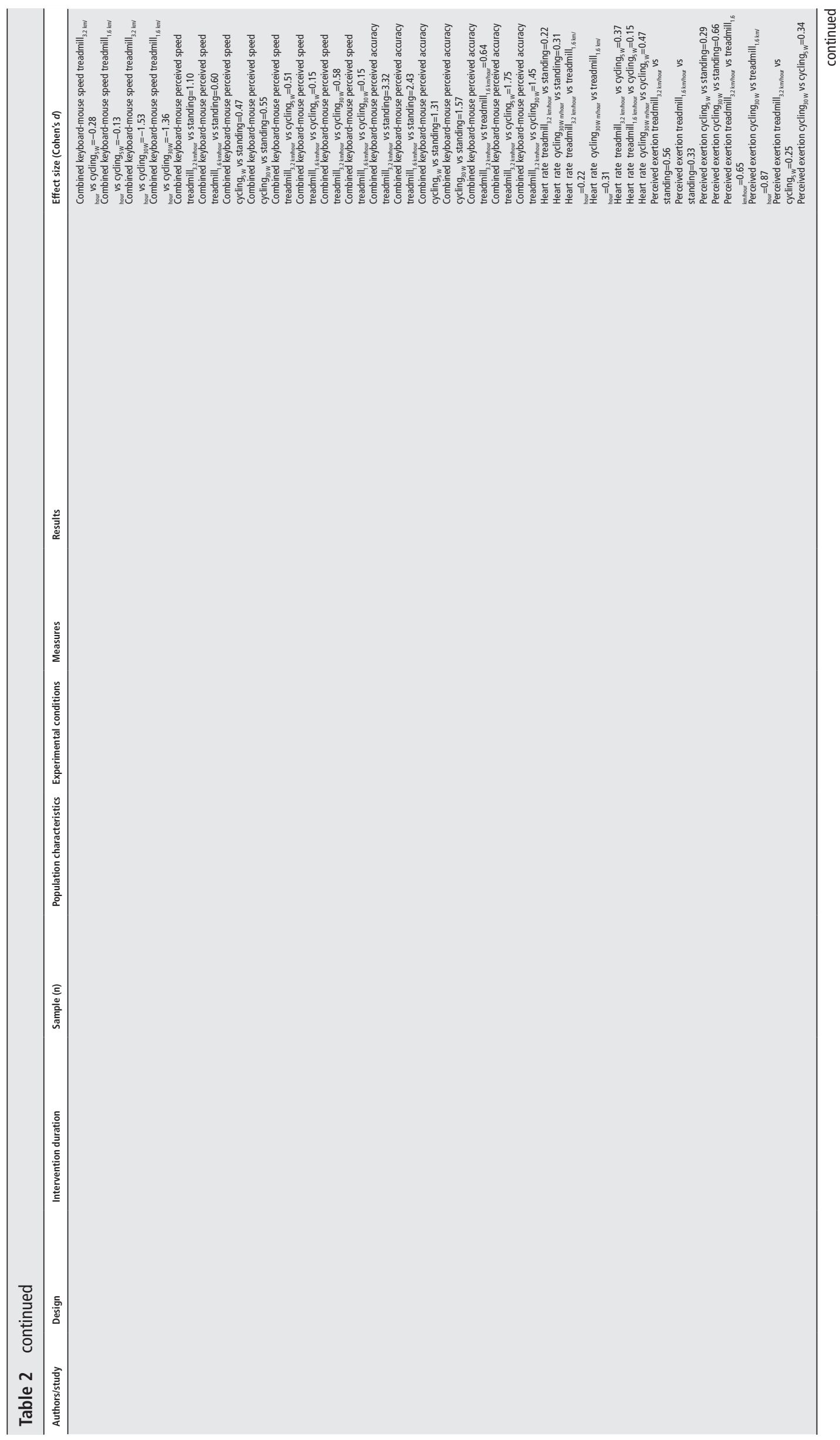




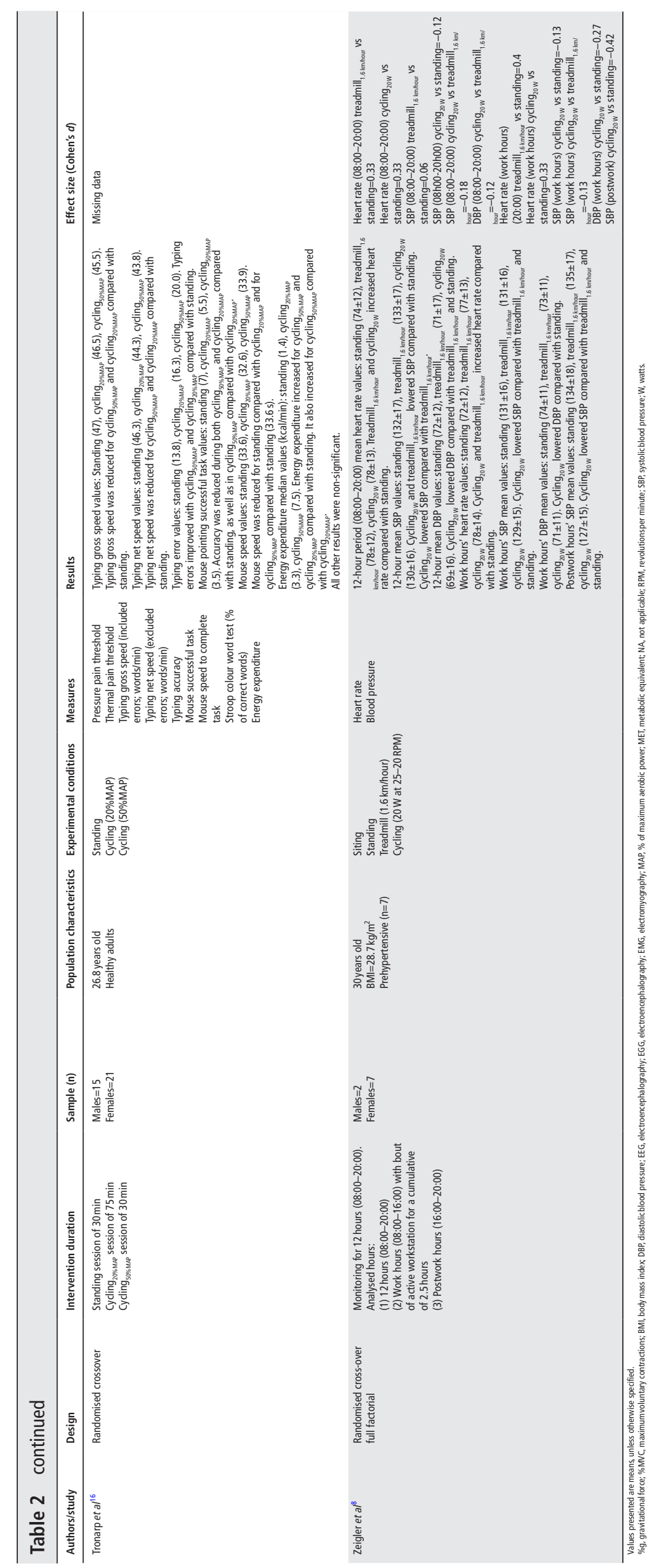




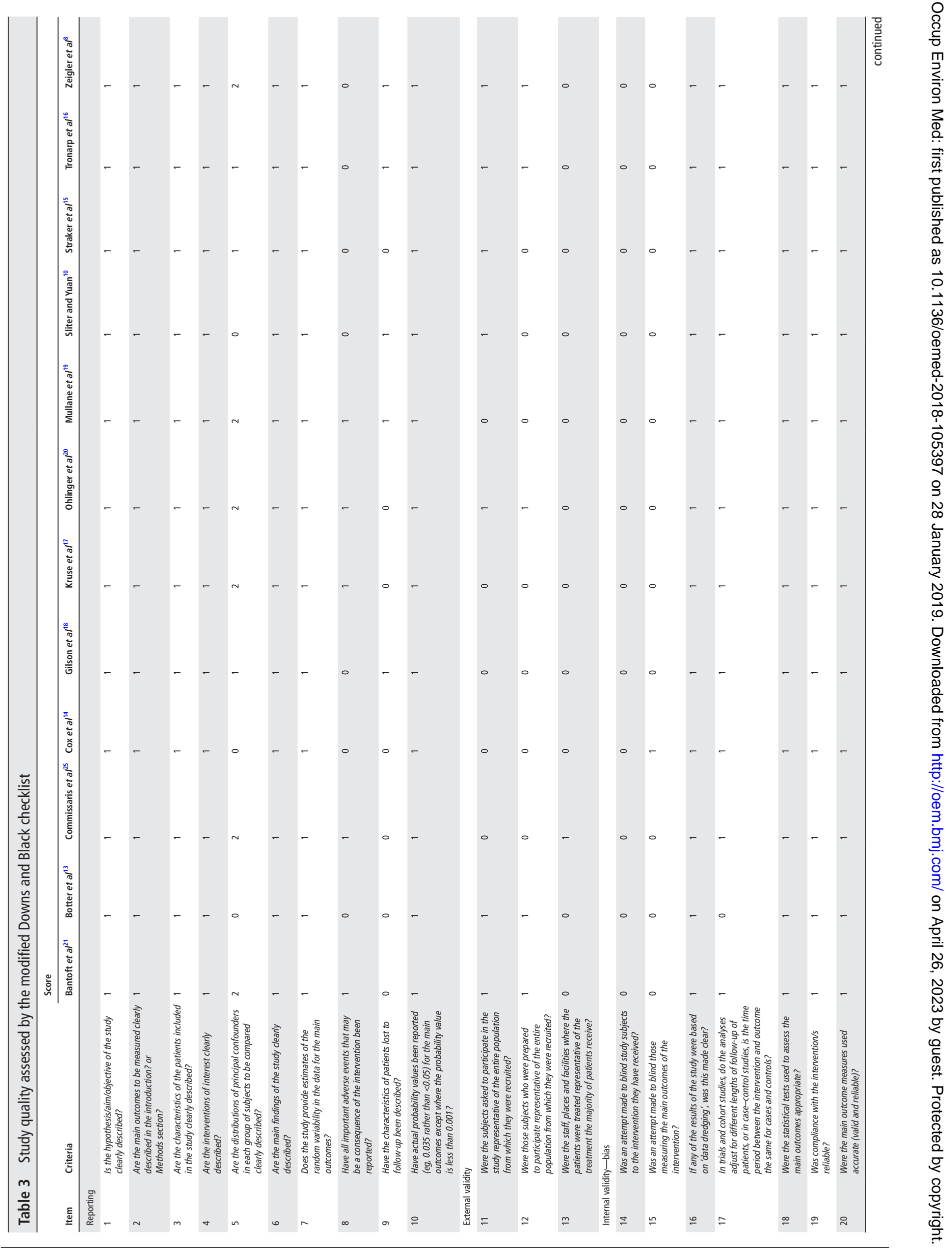




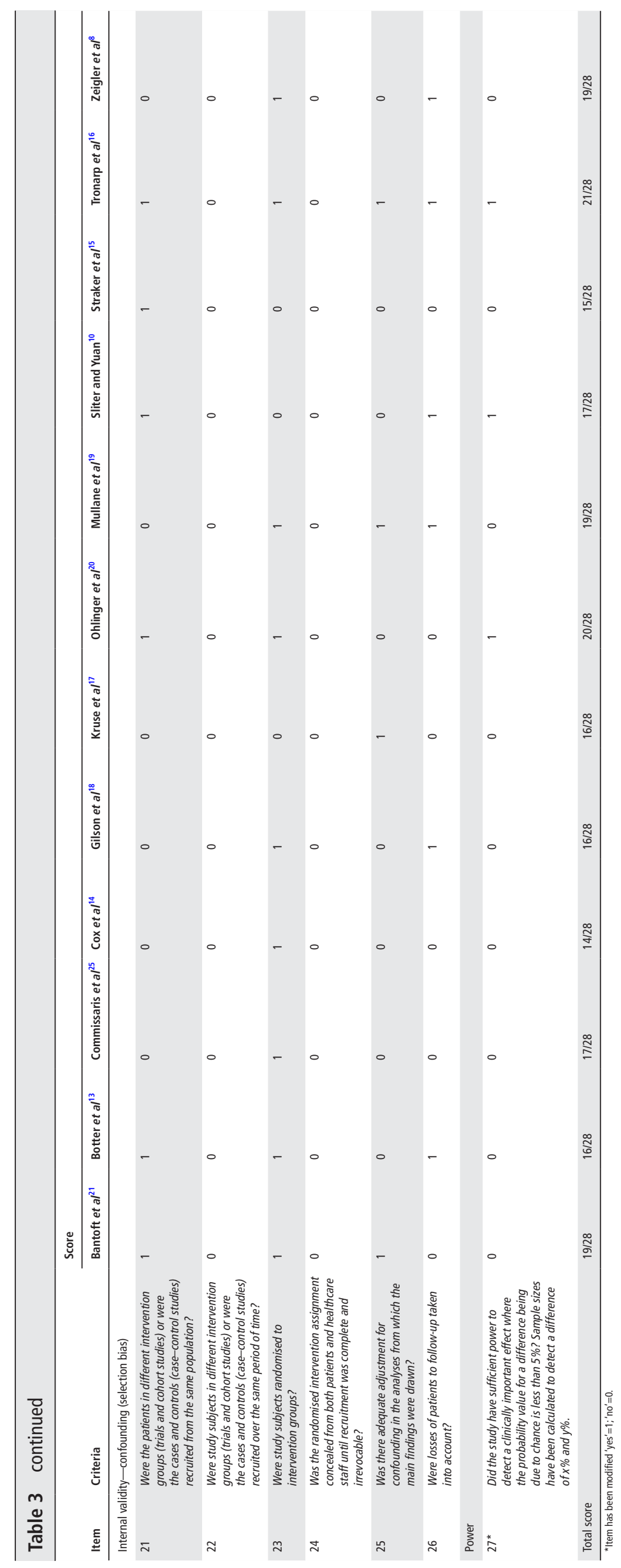


hours (16:00-20:00)). Results from the 12-hour period showed an increase of $4 \mathrm{bpm}$ for both treadmill $1_{1.6 \mathrm{~km} / \mathrm{hour}}$ and cycling ${ }_{20} \mathrm{w}$ conditions compared with standing. Results from the working hour-specific period showed an increase of $5 \mathrm{bpm}$ for treadmill ${ }_{1.6}$ $\mathrm{km} / \mathrm{hour}$ and $6 \mathrm{bpm}$ for cycling $\mathrm{g}_{20 \mathrm{w}}$ compared with standing. Results from postwork period showed no difference in HR between conditions.

\section{Blood pressure}

Two studies ${ }^{814}$ with different populations and active workstations examined mean systolic blood pressure (SBP) and mean diastolic blood pressure (DBP). Cox et al ${ }^{14}$ found no difference in SBP and DBP measured during an intervention comparing standing and treadmill workstations. The second study ${ }^{8}$ monitored ambulatory blood pressure on adults with overweight or class 1 obesity meeting prehypertensive or impaired fasting glucose criteria over a 12-hour period (08:00-20:00). During the 12-hour period, a reduction of $2 \mathrm{~mm} \mathrm{Hg}$ for cycling $20 \mathrm{w}$ and $1 \mathrm{~mm} \mathrm{Hg}$ for treadmill $1_{1.6 \mathrm{~km} / \mathrm{hour}}$ was reported in SBP compared with standing. For the work hour period (08:00-16:00), a decrease in SBP of $2 \mathrm{~mm} \mathrm{Hg}$ was reported for cycling ${ }_{20} \mathrm{w}$ compared for both treadmill ${ }_{16 \mathrm{~km} h o u r}$ and standing workstations. In the postwork period (16:00-20:00), there was a greater decrease in SBP compared with the two periods mentioned above. SBP for cycling $_{20 \mathrm{w}}$ decreased by $8 \mathrm{~mm} \mathrm{Hg}$ compared with treadmill $1_{1.6 \mathrm{~km} /}$ hour and $9 \mathrm{~mm} \mathrm{Hg}$ compared with the standing workstation. DBP was similar between standing and treadmill $1_{1.6 \mathrm{~km} / \mathrm{hour}}$ conditions for all three periods. However, cycling 20 w decreased DBP by $3 \mathrm{~mm} \mathrm{Hg}$ compared with standing, and $2 \mathrm{~mm} \mathrm{Hg}$ compared with treadmill $1_{1.6 \mathrm{~km} / \text { hour }}$ workstations for the 12-hour period as well as decreased DBP by $3 \mathrm{~mm} \mathrm{Hg}$ compared with standing during working hours.

\section{Energy expenditure}

Energy expenditure and $\mathrm{VO}_{2}$ were measured in three studies. ${ }^{13} 1416$ Botter $e$ e $a l^{13}$ showed an increase in energy expenditure of 1.2 metabolic equivalent (MET) for treadmill $2.5 \mathrm{~km} / \mathrm{hour}$ workstations compared with standing. Cox et $a l^{14}$ measured a similar increase of 1 MET from standing to treadmill ${ }_{161 \mathrm{~km} / \mathrm{hour}}$. Tronarp et $a l^{16}$ measured energy expenditure in kcal. In this study, energy expenditure increased between all three conditions: an increase of $2.9 \mathrm{kcal} / \mathrm{min}$ between cycling ${ }_{20 \% \mathrm{MAP}}$ and standing; an increase of $6.9 \mathrm{kcal} / \mathrm{min}$ between cycling ${ }_{50 \% \mathrm{MAP}}$ and standing.

\section{Perceived exertion and pain tolerance}

Two studies ${ }^{14} 15$ measured perceived exertion, both using the 10-point Borg Scale. In the first study, Cox et al ${ }^{14}$ reported an increase in perceived effort and perceived breathlessness (ie, dyspnoea) on the treadmill compared with standing for all tasks, namely warm-up, silent reading, reading aloud and speaking aloud spontaneously. The second study ${ }^{15}$ reported higher perceived exertion for treadmill $1_{1.6 \mathrm{~km} / \text { hour }}(1.74 / 10)$, treadmill 3.2 km/hour $(2.39 / 10)$, cycling $5_{5}$ (1.66/10) and cycling $30 \mathrm{w}(2.61 / 10)$ compared with standing $(0.95 / 10)$. Furthermore, higher perceived exertion was reported for greater power and speed

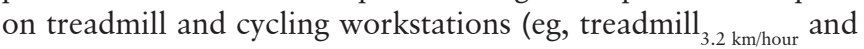
cycling $_{30 \mathrm{w}}$ compared with treadmill $_{1.6 \mathrm{~km} / \mathrm{hour}}$ and cycling 5 w).

Pressure pain threshold was measured in kilopascals $(\mathrm{kPa})$ using a Somedic algometer on the right quadriceps, right ventral forearm and right trapezius. ${ }^{16}$ Only differences in the pressure pain threshold of the right trapezius between standing $(16.8 \mathrm{kPa})$ and cycling ${ }_{20 \% \mathrm{MAP}}(39.3 \mathrm{kPa})$ were reported.

\section{Work performance}

Seven studies ${ }^{10} 15^{16}{ }^{18-21}$ reported cognitive outcomes. The authors measured perceived and actual task performances (eg, typing, mouse, psychomotor performances), attention and shortterm memory capacity as well as psychobiological (eg, arousal, boredom) outcomes.

\section{Perceived work performance}

One study ${ }^{15}$ reported perceived task performance. Studies observed perceived speed and accuracy of typing, mouse pointing and combined keyboard/mouse tasks. Perceived work performance was assessed with a questionnaire. Participants rated perceived effect of the use of diverse active workstations on a scale of $1-5$ (ie, $1=$ very enhanced to $5=$ very diminished). Results from the perceived typing questionnaire showed a decrease in performance for the treadmill $l_{1.6 \mathrm{~km} / \mathrm{hour}}$, treadmill $_{3.2 \mathrm{~km}}$ hour cycling $_{5 \mathrm{w}}$ and cycling ${ }_{30 \mathrm{w}}$ compared with standing. Perceived accuracy also decreased with the use of both treadmill $1_{1.6-3.2 \mathrm{~km} /}$ hour and cycling $_{5-30 \mathrm{w}}$ workstations compared with the standing workstation. In addition, a decline in perceived accuracy was

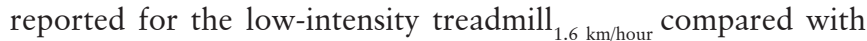
the low-intensity cycling ${ }_{5}$ condition.

Questionnaire outcomes for perceived mouse pointing speed showed a decrease for treadmill $1_{1.6 \mathrm{~km} / \mathrm{hour}}$, treadmill $l_{3.2 \mathrm{~km} / \mathrm{hour}}$, cycling $_{5 \text { W }}$ and cycling ${ }_{30 \mathrm{w}}$ compared with standing. Also, a reduction of perceived speed was observed for both treadmill $1_{1.6 \mathrm{~km}}$ hour and treadmill ${ }_{3.2 \mathrm{~km} / \text { hour }}$ compared with both cycling ${ }_{5} \mathrm{w}$ and cycling $_{30 \mathrm{w}}$ conditions. There was a decline for the treadmill ${ }_{1.6}$ km/hour, treadmill ${ }_{3.2 \mathrm{~km} / \text { hour }}$, cycling $\mathrm{w}_{5}$ and cycling $\mathrm{s}_{30 \mathrm{~W}}$ compared with standing in perceived mouse pointing accuracy. There was a reduction in perceived accuracy for both treadmill workstations compared with low-intensity cycling ${ }_{5} \mathrm{~W}$

Questionnaire outcomes for perceived combined keyboard/ mouse speed tasks showed a decrease in perceived speed for treadmill $_{1.6 \mathrm{~km} / \mathrm{hour}}$, treadmill ${ }_{3.2 \mathrm{~km} / \mathrm{hour}}$, cycling 5 w and cycling ${ }_{30 \mathrm{~W}}$ compared with standing. In addition, a decline in perceived speed for both treadmill workstation conditions compared with both cycling workstation conditions was observed. Perceived accuracy decreased for the treadmill $1_{1.6 \mathrm{~km} / \text { hour }}$, treadmill $_{3.2 \mathrm{~km} / \text { hour }}$, cycling ${ }_{5} \mathrm{w}$ and cycling ${ }_{30 \mathrm{w}}$ compared with standing. Moreover, perceived accuracy declined for treadmill $3.2 \mathrm{kmhhour}$ compared with the lower intensity treadmill $1_{1.6} \mathrm{~km} / \mathrm{hour}$ and both cycling workstation conditions.

\section{Actual performance tasks}

Three studies ${ }^{151620}$ examined the effect of active workstations on typing performance. Straker $e t a l^{15}$ examined the effect of active workstations on typing speed performance (words/min) and accuracy (\% of typing errors). Typing speed was reduced for

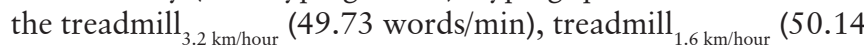
words $/ \mathrm{min})$, cycling 5 w $(53.17$ words $/ \mathrm{min})$ and cycling ${ }_{30 \mathrm{w}}(52.58$ words/min) compared with standing (54.09 words/min). No differences were reported for the accuracy test. Tronarp et al ${ }^{16}$ found that gross speed (ie, including erased typing errors) was reduced for the cycling ${ }_{50 \% \mathrm{MAP}}(45.5$ words $/ \mathrm{min})$ and cycling ${ }_{20 \% \mathrm{MAP}}$ (46.5 words/min) compared with standing (47.0 words/ min). Net speed (ie, excluding erased typing errors) was also reduced for cycling ${ }_{50 \% \mathrm{MAP}}\left(43.8\right.$ words/min) and cycling ${ }_{20 \% \mathrm{MAP}}$ (44.3 words $/ \mathrm{min}$ ) compared with standing (46.3 words/min). Moreover, typing errors (ie, number of errors) increased with both cycling 50\%MAP (20) and cycling 20\%MAP (16.3) compared with standing (13.8). No differences were reported between cycling $_{50 \% \mathrm{MAP}}$ and cycling ${ }_{200 \% \mathrm{MAP}}$ Ohlinger et al ${ }^{20}$ measured the 
number of taps in a $10 \mathrm{~s}$ trial. A reduction in taping speed was observed for the treadmill workstation (55.8) compared with the standing workstation (57.0). To resume, all three studies observed decreases in typing speed with treadmill workstations compared with a standing workstation. The two studies ${ }^{15} 16$ with cycling conditions observed a decrease in typing speed compared with a standing workstation. Only one study ${ }^{16}$ observed a decrease in typing word accuracy with the use of cycling workstations compared with a standing workstation.

Two studies ${ }^{15} 16$ examined mouse pointing speed (ie, milliseconds) and accuracy (ie, actual errors). The first study ${ }^{15}$ reported a decrease in speed for treadmill $1_{1.6 \mathrm{~km} / \mathrm{hour}}(1059 \mathrm{~ms})$; treadmill $_{3.2 \mathrm{~km} / \text { hour }}(1107 \mathrm{~ms})$; and cycling 5 w $(1022 \mathrm{~ms})$ compared with standing $(959 \mathrm{~ms})$. Similar values were reported for cycling $\mathrm{w}_{5}$ and cycling $_{30 \mathrm{w}}$ workstations $(1022 \mathrm{~ms})$. Both treadmill $1.6-3.2 \mathrm{~km} /$ hour workstations resulted in decreased mouse pointing speed compared with both cycling ${ }_{5-30}$ w workstations. Furthermore,

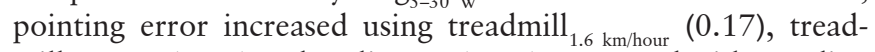
mill $_{3.2 \mathrm{~km} / \text { hour }}(0.20)$ and cycling ${ }_{30 \mathrm{w}}(0.16)$ compared with standing $(0.10)$, and for treadmill $3.2 \mathrm{~km} / \mathrm{hour}(0.20)$ compared with cycling $\mathrm{w}_{5}$ (0.13). To resume this study observed that mouse pointing speed and accuracy decreased with treadmill workstations compared with a standing workstation. In addition, mouse pointing speed decreased with the use of treadmill workstations compared with cycling workstations. The second study ${ }^{16}$ reported a decrease in mouse pointing speed for standing $(33.6 \mathrm{~ms})$ compared with cycling $_{20 \% \text { MAP }}(32.6 \mathrm{~ms})$. But contrary to the last study, a decrease in mouse pointing speed was reported for a higher cycling 50\%MAP intensity $(33.9 \mathrm{~ms})$ compared with standing $(33.6 \mathrm{~ms})$. Accuracy was assessed by the number of successful tasks. Results showed a reduction of successful tasks during both cycling ${ }_{50 \% \text { MAP }}(3.5)$ and cycling $_{20 \% \mathrm{MAP}}(5.5)$ compared with standing (7), and a decrease in

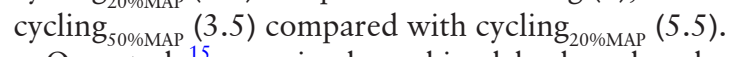

One study ${ }^{15}$ examined combined keyboard and mouse task performance (ie, speed (words/s) and error rate). A decrease in speed was observed for both treadmill $1_{1.6 \mathrm{~km} / h o u r}(9.57$ words/s) and treadmill $\mathrm{3}_{3.2 \mathrm{~km} / \mathrm{hour}}(8.26$ words/s) compared with standing (11.94 words/s). Furthermore, a decrease in speed was observed for the treadmill ${ }_{1.6 \mathrm{~km} / h o u r}(9.57$ words $/ \mathrm{s})$ and treadmill ${ }_{3.2 \mathrm{~km} / \mathrm{hour}}(8.26$ words/s) conditions compared with the cycling ${ }_{5 \mathrm{~W}}(10.84$ words/s) and cycling $_{30 \mathrm{w}}(11.17$ words/s) conditions. No differences in error rate were reported between active workstations.

\section{Processing speed tasks}

Processing speed tasks were assessed in one study. ${ }^{19}$ Researchers used a psychomotor test (ie, detection test from Cogstate) to measure speed and reaction time to accomplish a simple task. Standing z-score and treadmill $1.6 \mathrm{~km} /$ hour $\mathrm{z}$-score showed a lower speed of performance than cycling $20 \mathrm{w} z$-score. Cycling ${ }_{20}$ w reaction time was faster than standing reaction time.

\section{Attention and short memory}

Out of the four studies ${ }^{18-21}$ that examined the influence of active workstations on attention and short-term memory capacity, none found differences between active workstations (ie, standing, treadmill and cycling) in selective attention. Moreover, divided attention and short-term auditory verbal memory revealed no differences between standing, treadmill and cycling workstations.

\section{Psychobiological}

One study ${ }^{10}$ reported psychobiological outcomes. With a 4 rating scale questionnaire, this study evaluated the level of arousal, boredom, stress and task satisfaction (eg, $1=$ definitely no to $4=$ definitely yes). The authors reported that treadmill workstations increased arousal compared with standing as well as cycling compared with standing. Boredom decreased with treadmill and cycling workstations compared with standing. Stress scores showed that treadmill workstations lowered stress compared with standing.

\section{DISCUSSION}

The purpose of this review article was to compare the benefits between standing, treadmill and cycling workstations. This article reviewed 12 studies. Our main findings were that: (1) the benefits associated with standing, treadmill and cycling workstations may not be equivalent; (2) cycling and treadmill workstations appear to provide greater short-term physiological changes than standing workstations that could potentially lead to better health; and (3) cycling, treadmill and standing workstations appear to show productivity benefits while treadmill workstations seem to diminish the performance of work-related use of computers.

\section{Cycling workstation}

Cycling workstations with resistance (ie, 20-30 W) can increase energy expenditure by twice the amount of MET compared with standing workstations. ${ }^{13}$ Likewise, related to energy expenditure, HR could be increased by $10 \%$ compared with standing workstations. ${ }^{13} 15$ Also pertinent, one study reported that cycling workstations with the same HR and energy expenditure as treadmill workstations produced a greater decrease in ambulatory blood pressure in adults presenting with obesity and a prehypertension. ${ }^{8}$ Moreover, cycling was the only active workstation that decreased DBP. Although cardiometabolic benefits accompany 20-30 W of resistance, a lower intensity (ie, $5 \mathrm{~W}$ ) does not provide any advantages over standing or treadmill conditions. ${ }^{15}$ Also, bouts of $10 \mathrm{~min} /$ hour using a cycling workstation are not enough to reverse the negative effects of prolonged sitting time on lower limb endothelial dysfunction. ${ }^{17}$

Cycling workstations increase arousal and reduce boredom significantly better than standing workstations. ${ }^{10}$ These outcomes are relevant as research has reported an interaction between level of physical activity at work, well-being at work and work productivity. ${ }^{223}$ Furthermore, one study has proposed that cycling workstations could be capable of increasing shortterm memory and attention more effectively than standing or treadmill workstations. ${ }^{19}$

No reductions in motor task performance were reported with the use of cycling workstations. ${ }^{15}{ }^{24-27}$ Speed processing time in simple tasks does increase compared with treadmill and standing conditions. ${ }^{19} 28$ These productivity results are important as cycling workstations, compared with treadmill and standing workstations, allow workers to experience greater cardiometabolic gains, while maintaining acceptable levels of productivity in office tasks.

\section{Treadmill workstation}

Treadmill workstations with speeds between 1.6 and $2.5 \mathrm{~km} /$ hour raise energy expenditure by about 1 MET beyond standing workstations and the sedentary threshold (1.5 MET). Also, with greater intensity (ie, $3.2 \mathrm{~km} /$ hour), treadmill workstations can increase HR similar to what is found for cycling workstations at $30 \mathrm{~W}$ of resistance. However, at this speed, the increase in perceived exertion and discomfort decreases implementation feasibility and motor task performance. Furthermore, the use of 
treadmills compared with standing workstations decreases SBP while no difference is found for DBP. ${ }^{8} 14$

Compared with standing workstations, treadmill workstations can positively influence many psychological components related to the work environment. A reduction in task stress, an increase in arousal, a lower feeling of boredom and a higher feeling of task satisfaction were reported by participants based on a single study. ${ }^{10}$ More studies are required to clarify the effects of low-intensity exercise similar to the effects described for treadmill workstations on workers' mood. Some of these improvements may be explained by the increase in cardiovascular activity associated with an active workstation, possibly contributing to improved brain oxygenation, hence an improvement in cognitive tasks (memorisation and attention). ${ }^{11}{ }^{29-33}$ However, the results of the current review did not provide evidence of any cognitive benefits from treadmill compared with cycling or standing workstations.

With treadmill workstations, executive motor task performance, such as typing, or mouse pointing was reduced. ${ }^{15} 2534$ Higher walking speeds $(3.2 \mathrm{~km} /$ hour$)$ produced greater muscular activity in the upper limbs than that observed in standing or cycling workstations. This increase in muscular demand of the trunk muscles and upper limb muscles in order to stabilise posture and gait may affect motor coordination related to computer tasks ${ }^{13} 35$ and could lead to muscular fatigue and muscle tension. ${ }^{13}$ In this context, safety issues should be raised, and further studies are required to ensure the safety of workers using treadmill desks.

\section{Standing workstation}

Several studies suggest that standing workstations can decrease sitting time at work. ${ }^{633}$ As a result, even if standing workstations do not exceed a sedentary threshold (ie, energy expenditure), ${ }^{37}$ postprandial glycaemia excursion and blood pressure $^{83839}$ are improved compared with conventional seated workstations. It is known that prolonged sitting can potentially cause low back pain due to lumbar flexion. A standing position inhibits lumbar flexion. Periods of time on a standing workstation have shown to be preventive against such injuries at work. ${ }^{940}$ Interestingly, contrary to a treadmill workstation, the upright posture from standing workstations does not alter executive office tasks such as typing and mouse pointing. Moreover, standing workstations do not increase perceived exertion or reduce the efficiency of computer tasks. Furthermore, studies suggest that globally, standing workstations do not alter cognitive performance tasks. ${ }^{3341}$

\section{Perspectives and limits}

Active workstations are a novel intervention. The comparison of active workstations was available in 12 studies and only 11 specifically compared outcomes between active workstations. Also, the findings of this literature review are supported by shortterm measures only. In addition, a large number of outcomes were provided by only one or two studies which both had relatively small sample sizes. As mentioned by other authors, ${ }^{42}$ larger randomised controlled trials with mid-term and long-term protocols are needed to provide stronger evidence.

\section{CONCLUSIONS}

The benefits associated with standing, treadmill and cycling workstations may not be equivalent. Cycling and treadmill workstations appear to provide greater short-term physiological improvements compared with standing, which could potentially lead to better health outcomes. Cycling, treadmill and standing workstations appear to show short-term productivity benefits; however, treadmill workstations reduce the performance of computer-related work.

With workers and the workplace slowly moving towards active workstations, future long-term studies integrating different types of active workstations should be conducted in order to provide additional evidence. Ultimately, workers and corporations should be able to critically examine the benefits and limitations of each type of workstation and determine which is most appropriate for the worker's specific needs and tasks.

Acknowledgements The authors acknowledge the following individuals who contributed significant time and effort to the consensus development process and to the preparation of this manuscript: Denis Arvisais, Ryan Reid, Thiffya Arabi Kugathasan, Grant FIT24-Healthy and Productive Work Initiative (No 146019) by Social Sciences and Humanities Research and Canadian Institutes of Health Research.

Contributors FD and FL performed the literature review. FD and MEM designed the project. FD provided the first draft of the paper. All the authors revised and approved the manuscript.

Funding Grant FIT24-Healthy and Productive Work Initiative (No 146019) by Social Sciences and Humanities Research and Canadian Institutes of Health Research.

Competing interests None declared.

Patient consent for publication Not required.

Provenance and peer review Not commissioned; externally peer reviewed.

\section{REFERENCES}

1 Ding D, Lawson KD, Kolbe-Alexander TL, et al. The economic burden of physical inactivity: a global analysis of major non-communicable diseases. The Lancet 2016;388:1311-24.

2 Choi B, Schnall PL, Yang H, et al. Sedentary work, low physical job demand, and obesity in US workers. Am J Ind Med 2010;53:1088-101.

3 Parry S, Straker $L$. The contribution of office work to sedentary behaviour associated risk. BMC Public Health 2013;13:296.

$4 \mathrm{Chu} \mathrm{AH}, \mathrm{Ng} \mathrm{SH}$, Tan CS, et al. A systematic review and meta-analysis of workplace intervention strategies to reduce sedentary time in white-collar workers. Obes Rev 2016;17:467-81.

5 Hutcheson AK, Piazza AJ, Knowlden AP. Work site-based environmental interventions to reduce sedentary behavior: a systematic review. Am J Health Promot 2018:32:32-47.

6 Neuhaus M, Eakin EG, Straker L, et al. Reducing occupational sedentary time: a systematic review and meta-analysis of evidence on activity-permissive workstations. Obes Rev 2014;15:822-38.

7 Tudor-Locke C, Schuna JM, Frensham LJ, et al. Changing the way we work: elevating energy expenditure with workstation alternatives. Int J Obes 2014;38:755-65.

8 Zeigler ZS, Mullane SL, Crespo NC, et al. Effects of standing and light-intensity activity on ambulatory blood pressure. Med Sci Sports Exerc 2016;48:175-81.

9 Ognibene GT, Torres W, von Eyben R, et al. Impact of a sit-stand workstation on chronic low back pain. J Occup Environ Med 2016;58:287-93.

10 Sliter M, Yuan Z. Workout at work: laboratory test of psychological and performance outcomes of active workstations. J Occup Health Psychol 2015;20:259-71.

11 Labonté-LeMoyne Élise, Santhanam R, Léger P-M, et al. The delayed effect of treadmill desk usage on recall and attention. Comput Human Behav 2015;46:1-5.

12 Downs SH, Black N. The feasibility of creating a checklist for the assessment of the methodological quality both of randomised and non-randomised studies of health care interventions. J Epidemiol Community Health 1998;52:377-84.

13 Botter J, Ellegast RP, Burford EM, et al. Comparison of the postural and physiological effects of two dynamic workstations to conventional sitting and standing workstations. Ergonomics 2016;59:449-63.

$14 \mathrm{Cox} \mathrm{RH}$, Guth J, Siekemeyer L, et al. Metabolic cost and speech quality while using an active workstation. J Phys Act Health 2011:8:332-9.

15 Straker L, Levine J, Campbell A. The effects of walking and cycling computer workstations on keyboard and mouse performance. Hum Factors 2009:51:831-44.

16 Tronarp R, Nyberg A, Hedlund M, et al. Office-cycling: a promising way to raise pain thresholds and increase metabolism with minimal compromising of work performance. Biomed Res Int 2018;2018:1-12.

17 Kruse NT, Hughes WE, Benzo RM, et al. Workplace strategies to prevent sittinginduced endothelial dysfunction. Med Sci Sports Exerc 2018;50:801-808.

18 Gilson ND, Hall C, Renton A, et al. Do sitting, standing, or treadmill desks impact psychobiological indicators of work productivity? Journal of Physical Activity and Health 2017;14:793-6. 
19 Mullane SL, Buman MP, Zeigler ZS, et al. Acute effects on cognitive performance following bouts of standing and light-intensity physical activity in a simulated workplace environment. J Sci Med Sport 2017;20:489-93.

20 Ohlinger CM, Horn TS, Berg WP, et al. The effect of active workstation use on measures of cognition, attention, and motor skill. J Phys Act Health 2011;8:119-25.

21 Bantoft C, Summers MJ, Tranent PJ, et al. Effect of standing or walking at a workstation on cognitive function: a randomized counterbalanced trial. Hum Factors 2016:58:140-9.

22 Michishita R, Jiang Y, Ariyoshi D, et al. The practice of active rest by workplace units improves personal relationships, mental health, and physical activity among workers. J Occup Health 2017;59:122-30.

23 Puig-Ribera A, Martínez-Lemos I, Giné-Garriga M, et al. Self-reported sitting time and physical activity: interactive associations with mental well-being and productivity in office employees. BMC Public Health 2015;15:72.

24 J. Carr L, Maeda H, Luther B, et al. Acceptability and effects of a seated active workstation during sedentary work. Int J Workplace Health Manag 2014;7:2-15.

25 Commissaris DA, Könemann R, Hiemstra-van Mastrigt S, et al. Effects of a standing and three dynamic workstations on computer task performance and cognitive function tests. App/ Ergon 2014;45:1570-8.

26 Elmer SJ, Martin JC. A cycling workstation to facilitate physical activity in office settings. App/ Ergon 2014;45:1240-6.

27 Cho J, Freivalds A, Rovniak LS. Utilizing anthropometric data to improve the usability of desk bikes, and influence of desk bikes on reading and typing performance. Appl Ergon 2017;60:128-35.

28 Torbeyns T, de Geus B, Bailey S, et al. Cycling on a bike desk positively influences cognitive performance. PLoS One 2016;11:e0165510.

29 Giles GE, Brunyé TT, Eddy MD, et al. Acute exercise increases oxygenated and deoxygenated hemoglobin in the prefrontal cortex. Neuroreport 2014;25:1320-5.

30 Ouchi Y, Okada H, Yoshikawa E, et al. Absolute changes in regional cerebral blood flow in association with upright posture in humans: an orthostatic PET study. J NuCl Med 2001;42:707-12.
31 Rooks CR, Thom NJ, McCully KK, et al. Effects of incremental exercise on cerebral oxygenation measured by near-infrared spectroscopy: a systematic review. Prog Neurobiol 2010;92:134-50.

32 Tomporowski PD. Effects of acute bouts of exercise on cognition. Acta Psychol 2003;112:297-324.

33 MacEwen BT, MacDonald DJ, Burr JF. A systematic review of standing and treadmill desks in the workplace. Prev Med 2015;70:50-8.

34 Funk RE, Taylor ML, Creekmur CC, et al. Effect of walking speed on typing performance using an active workstation. Percept Mot Skills 2012;115:309-18.

35 Fedorowich LM, Emery K, Côté JN. The effect of walking while typing on neck/ shoulder patterns. Eur J App/ Physio/ 2015;115:1813-23.

36 Alkhajah TA, Reeves MM, Eakin EG, et al. Sit-stand workstations: a pilot intervention to reduce office sitting time. Am J Prev Med 2012;43:298-303.

37 Mansoubi M, Pearson N, Clemes SA, et al. Energy expenditure during common sitting and standing tasks: examining the 1.5 MET definition of sedentary behaviour. BMC Public Health 2015;15:516.

38 Bouchard DR, Strachan S, Johnson L, et al. Using shared treadmill workstations to promote less time spent in daily low intensity physical activities: a pilot study. J Phys Act Health 2016;13:111-8.

39 Buckley JP, Mellor DD, Morris M, et al. Standing-based office work shows encouraging signs of attenuating post-prandial glycaemic excursion. Occup Environ Med 2014;71:109-11.

40 Karakolis T, Barrett J, Callaghan JP. A comparison of trunk biomechanics, musculoskeletal discomfort and productivity during simulated sit-stand office work. Ergonomics 2016;59:1275-87.

41 Russell BA, Summers MJ, Tranent PJ, et al. A randomised control trial of the cognitive effects of working in a seated as opposed to a standing position in office workers. Ergonomics 2016;59:737-44.

42 Shrestha N, Kukkonen-Harjula KT, Verbeek JH, et al. Workplace interventions for reducing sitting at work. Cochrane Database Syst Rev 2018;6:CD010912. 